\title{
Formation of harmful volatile substances in sewage systems and their neutralization
}

\author{
Vladimir Orlov and Sergey Zotkin* \\ Moscow State University of Civil Engineering, Yaroslavskoe shosse, 26, Moscow, 129337, Russia
}

\begin{abstract}
The study of the ways of harmful volatile substance formation in sewerage systems, as well as a rapid and economical neutralization of these substances by construction, mechanical, physical and chemical, hydrodynamic and other methods is an urgent task that contributes to the protection of humans and the environment from toxic pollutants. The purpose of the presented studies is evaluation of the effectiveness of the impact on harmful volatile substances, through application of various methods designed to completely eliminate the conditions for the occurrence of odors harmful to human health or significantly reduce their amount to the maximum permissible concentrations in the airspace of cities. The methods have considered the description of the available ways of the odor identification by chemical and organoleptic analysis. The results provide a description of methods for blocking the formation of volatile substances. The operational works (methods of pipeline cleaning, ventilation, dosing of chemicals in waste waters) have been considered as the blocking measures, and the construction design ones (reconstruction of networks and facilities, biological, thermal, catalytic, electro-physical and other gas treatment methods) have been considered as the ways to reduce the spread of noxious odors. As a conclusion, it is noted that the complete elimination of the harmful volatile substance problem is possible by taking comprehensive measures to eliminate (minimize) the emission of gases into the environment.
\end{abstract}

\section{Introduction}

The urban sewerage systems that provide removal of the domestic wastewater are traditionally gravitational, which in some cases leads to negative consequences. The selfflowing movement of water in pipes represents two phases: water and air. The water acts as a transport medium and the air provides oxygen for the life of bacteria that are involved in the organic substance decomposition. The gravity flowing of sewage liquids in indoor and outdoor pipelines, as a rule, is combined with the pipeline ventilation as the result of the pipeline internal space contact with the atmospheric air. The outdoor air can also enter a sewer system through leaky well covers.

\footnotetext{
* Corresponding author: zotkinsp@mgsu.ru
} 
The increase in the development of urban constructions makes the outdoor pipelines longer, and, consequently, the water retention in them is longer too. The microbial environment rapidly inhabits the wastewater giving birth to the biological treatment process. Since the pipelines are partially filled with oxygen highly saturated air, the microbial medium is mostly represented by aerobic bacteria.

The formation of odors has a biochemical basis. The wastewater coming through pipelines to treatment facilities contains relatively high concentrations of organic substances, measured by chemical and biological limit concentrations, but with a limited amount of the dissolved oxygen. The actual rate of the oxygen depletion depends on the aerobic respiration rate and the re-aeration rate. As a rule, for domestic wastewater, the aerobic respiration rates from 2 to $20 \mathrm{mg} / \mathrm{l} \mathrm{O}_{2} / \mathrm{h}$ at the ambient temperature [1]. The microorganisms that are usually present in wastewater receive energy through oxidation of organic substances. The result is the formation of gaseous nitrogen, carbon dioxide and an increased alkalinity. In the absence of oxygen and nitrates, sulfates and carbon dioxide act as the electron acceptors. This leads to the reactions forming hydrogen sulfide, mercaptans, volatile fatty acids and other reduced organic compounds. Many of them have a strong smell. Accumulation of reduced metabolic products in the wastewater is a sign of the rotting progress [2]. The decomposition products of complex organic substances give simpler organic and inorganic compounds, as well as gases. Complete oxidation of organic substances contained in wastewater occurs with an excess of oxygen, when carbon, hydrogen, sulfur, phosphorus, and other elements (except nitrogen) are oxidized to $\mathrm{CO}_{2}$, $\mathrm{H}_{2} \mathrm{O}, \mathrm{P}_{2} \mathrm{O}_{5}, \mathrm{SO}_{3}$, and nitrogen is converted into an ammonium salt [3]. When carboncontaining substances are oxidized in the presence of oxygen, the carbon dioxide and water are formed, and when proteins are oxidized, fatty acids and gases are formed [2]. During the biochemical processes in the waste liquid, the amount of dissolved oxygen decreases rapidly over time and the organic compound decomposition process begins under anaerobic conditions, which leads to the formation of organic acids, alcohols, biogas and other compounds in the dissolved state [4].

Bacterial decomposition of proteins and amino acids leads to the decay of sulfurcontaining amino acids and the release of hydrogen sulfide and mercaptans. Indole is the main giver of the fetid smell of feces [5]. In biogas, hydrogen sulfide $\mathrm{H}_{2} \mathrm{~S}$ (a highly toxic colorless gas with an unpleasant smell of rotten eggs) and dimethyl sulfide can be found in the highest concentrations [6]. Substances with extremely unpleasant, piercing odors (mercaptans) are found in the subsurface space of pipelines. For example, the threshold detection of the ethyl mercaptan in the air is $4.6^{*} 10^{-8} \mathrm{mg}$, so it is added to natural gas to detect the gas leaks in residential buildings and industrial premises [7].

Decomposition of nitrogen-containing organic compounds, such as urea or proteins, forms ammonia, a colorless gas with a sharp smell. It should be noted that in most cases, the smell is formed not by a single substance, but by a complex mixture of substances, from where it is often impossible to distinguish specific odorous compounds, most of which are not identified and do not have the maximum permissible concentration [8].

\section{Materials, equipment and methods}

To control the odors coming from the sewer system, use has been made of organoleptic methods with the appropriate set of devices. The odor is usually identified by qualitative means at the sample temperature of $20^{\circ} \mathrm{C}$ being described as fecal, putrid, kerosene, phenol, etc. The GOST 32673-2014 of the Russian Federation accepts the European odor unit as an intensity measurement unit for the odor stemming from the wastewater in $1 \mathrm{~m}^{3}\left(\mathrm{OU} / \mathrm{m}^{3}\right)$. $\mathrm{N}$-butanol is used as a reference substance for smell measurement. One European reference odor mass is equivalent to 23 micrograms of n-butanol [9] 
The quantitative determination of odors is carried out using olfactometry, which is a method of measuring the smell by the degree of its perception by a person. In olfactometry investigations the presence and intensity of an odor is evaluated by a group of experts trusting their olfactory organs. The measurements by an olfactometer allow to get an odor concentration in odor units $\left(\mathrm{OU} / \mathrm{m}^{3}\right)$ (Fig. 1).

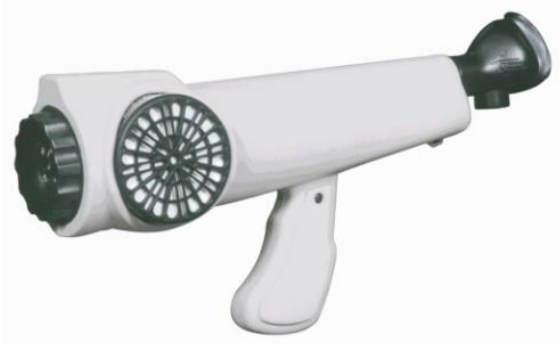

a)

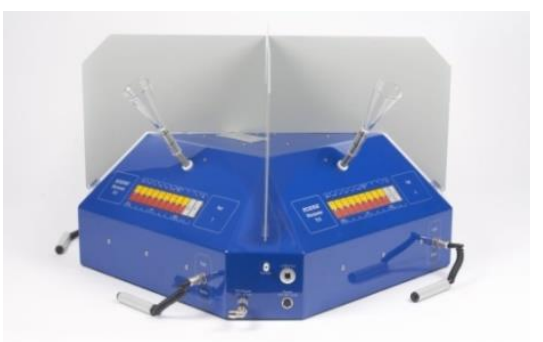

b)

Fig. 1. Mobile olfactometer (a) end laboratory olfactometer (b).

The principle of the utility operation consists in the displacement of the odorless atmospheric air and the filtered odorless air in discrete volume ratios called Dilution-toThreshold $(\mathrm{D} / \mathrm{T})$. The graduated $\mathrm{D} / \mathrm{T}$ disk allows discrete dilution to a threshold level at which the samples of the polluted odorous air are diluted 2, 4, 7, 15, 30, and 60 times [10, 11].

The smell monitoring is performed in places where odors are formed at the result of human activities and technological processes: in pressure and gravity pipelines, collectors, manholes, shafts, pumping stations and treatment facilities.

\section{Results and Discussions}

As the results of the research, the objects of odor emissions detected by olfactometry have been analyzed, as well as the methods for controlling harmful gases. Pipelines and collectors, pumping stations and treatment facilities are the main objects of gaseous emissions.

\subsection{Gravity pipelines}

The drainage pipe network is the main element of a sewage system. Natural aeration provides a constant supply of oxygen to the wastewater. A mandatory prescription to the internal sewerage pipelines is the control of the flow rate consistency, which excludes the failure of the pipe hydraulic valves on sanitary and household appliances which protect the occupants from the gas inflow into residential rooms. However, in recent years, the Russian regulations have introduced a wider range of conditions under which it is permissible not to equip each riser with an exhaust that extends to the roof of the building. The Russian Code of Rules (SP) 30.13330.2016 [12] includes the items aimed at reducing the number of ventilated risers in the buildings. So, the item 8.3.19 appoints that "Under an accurate justification it is allowed not to arrange an exhaust for the group of four risers and more combined on top. At the same time, it should be taken into account that such a combination makes the system unventilated." The introduction of this item simplifies the installation of the system, but does not solve the problem of removing odors and the outdoor sewer ventilation provision. Therefore, the item 8.3.21 prescribes that: "It is allowed to provide 
non-ventilated sewer risers and those with air anti-vacuum valves in the buildings and constructions".

The content of the dissolved oxygen decreases in case of the aeration process disorder, this means that the water rotting processes are observed. One of the main rot indicators is the presence of sulfides in the wastewater and (or) the content of hydrogen sulfide in the channel atmosphere, as well as in the exhaust air. The analysis of the gas occurrence and emission conditions shows that the formation and emissions of fetid gases are caused, first of all, by violation of the sufficient air inflow and the stream mode disorder such as blockages in pipes, sharp turns, mixing of different water qualitative types in the sewer system. It has been found, that two conditions are necessary for the rapid rotting progress in pipelines: an anaerobic environment and a large population of enzymatic and sulfurmetabolizing microorganisms [2].

The practice shows that it is possible to remove the source of an unpleasant smell from gravity pipelines by washing. In this case, the walls of the pipe are cleaned from the plaque, which processes the formation of fetidly smelling odors. Depending on the degree of the sewer pipeline contamination, the following methods of the sewer pipeline cleaning can be used: water-air; hydrodynamic by high-pressure water jets; hydro-cavitation; electrohydroimpulse, and others. If the odor formation is caused by a decrease in water consumption, it may be sufficient to reduce the diameter of the pipes by using trenchless technologies for dragging new polymer pipes of smaller diameter into the existing pipeline [13].

The collectors carry a significant load when transporting the wastewater to treatment facilities. Ventilation of collectors, as a rule, is provided through covers of lateral connection wells. During the operation, hydrogen sulfide is born in the biofilm on the inner surface of the pipeline walls. It rises to the arch of the pipe and reacts with water forming sulfuric acid, that leads to gradual wear of the pipes due to chemical corrosion of concrete and reinforced concrete. When organizing ventilation, the inflow of a cooler air from the day surface to the collectors occurs at the beginning of the aerodynamic section, and the release of the warmer (heated in the pipeline subsurface space) air saturated with aggressive gases - at the end of it. During transportation of the waste fluid through the sanitary collector, the filling increases due to the sewage inflow. This reduces the substructure gas volume, pressure and natural displacement of aggressive gases from a nearby pipeline shaft, that in some cases causes the damage of the shaft top overlapping [14-16].

In Russian and foreign regulatory documents, provision is made of necessary ventilation of the collector shafts $[12,17]$. In accordance with the standards, provision should be made of special exhaust utilities in the entrance chambers of underwater pipelines, manholes where the water flow rate sharply decreases in pipes with a diameter of more than $400 \mathrm{~mm}$, in drop wells with a drop height of more than $1 \mathrm{~m}$ and when the water flow rate is more than $50 \mathrm{l} / \mathrm{s}$, as well as in pressure lowering chambers. Ventilation of sewer channels and collectors of large cross-sections, including those laid by the shield method, should be taken according to special calculations.

\subsection{Wells and inverted siphons}

Manhole wells and inverted siphons are important elements for an effective sewage transportation. Given the gravitational flow mode in the wells, the problems with the appearance of sediments are similar to those in gravity sewer pipelines. If the flow rate is insufficient, sediments from the wastewater accumulate at the bottom of the manhole wells. Where ventilation is insufficient and the water has a high temperature, the process of the organic substance decomposition can begin. An excessive sealing of sewer wells is rather a negative factor, since this reduces the flow of oxygen to the wastewater. A special role is 
played by drop wells, which can be considered as an additional source of aeration, and if there is silting in adjacent pipelines, these wells become a source of the formed gas emissions. The practice shows that a possible solution to eliminate odors is to seal the manhole well covers or to re-lay pipeline sections changing their slope.

\subsection{Pump stations}

Unpleasant odors often come from pumping stations and pressure pipelines, especially at the points of transition from pressure to gravity flow mode. The recommended basic rules for designing and operating pumping stations are as follows [18]:

- in the receiving tank, the oxygen content of the incoming water must be maintained at the highest possible level; however, the waste water must not stagnate, as this leads to the formation of deposits and prevents the wastewater ventilation;

- the volume of the receiving tank, the power and the pump switching on should proceed according to the incoming wastewater flow rate and the pressure piping diameter to ensure, where possible, the minimal time of stagnation in the system;

- deep constructions complicate the wastewater ventilation; the pump suction chambers must be shaped so that on the one hand the water surface has a large area for oxygen to enter, and on the other hand there are minimal areas of the bottom and the walls exposed to the forming plaque;

- the formation of solid deposits and the plaque should be reduced by providing slopes that promote self-cleaning and continuous movement of the wastewater. The waste water should fall in a reservoir with a waterfall, providing an additional supply of oxygen, in the aerobic places. If the incoming water contains sulfides, it must be fed below the pump turning off level to enable the minimal turbulence and thus hydrogen sulfide emissions;

- the pump switching on/off time should be changed periodically; to determine the optimal pumping cycle, it is necessary to study the hydrogen sulfide formation in the waste water or the oxygen consumption;

- the gas space of the tanks must be equipped with supply and exhaust ventilation, in order to ensure the calculated air exchange and reliably divert the air flow coming together with the incoming waste water.

\subsection{Treatment facilities}

The treatment facilities are real "plants" for the production of biogas, the basis of which is methane [19]. One of the ways to get energy from the wastewater is to burn the biogas produced by anaerobic digestion of wastewater sediments in the methane tanks. For example, the Mosvodokanal joint-Stock Company (JSC) has been operating a mini-TPS since 2009, built at the Kuryanov treatment plants (CBS) and using the biogas as fuel [20].

Over the past decade, the Moscow sewage facilities have happened to be surrounded by a dense developing residential housing, which has led to an increased number of complaints from the population about the appearance of unpleasant odors. In order to improve the quality of the human life, Mosvodokanal JSC has developed and has been widely implementing a "Program for removing odors from sewage facilities". One of the directions of this program is to prevent the emission of fetidly smelling gases from sewage treatment facilities having a large evaporation surface. The implementation of floating floorings over the treatment facilities may be given as an example (Fig. 2) [20]. 


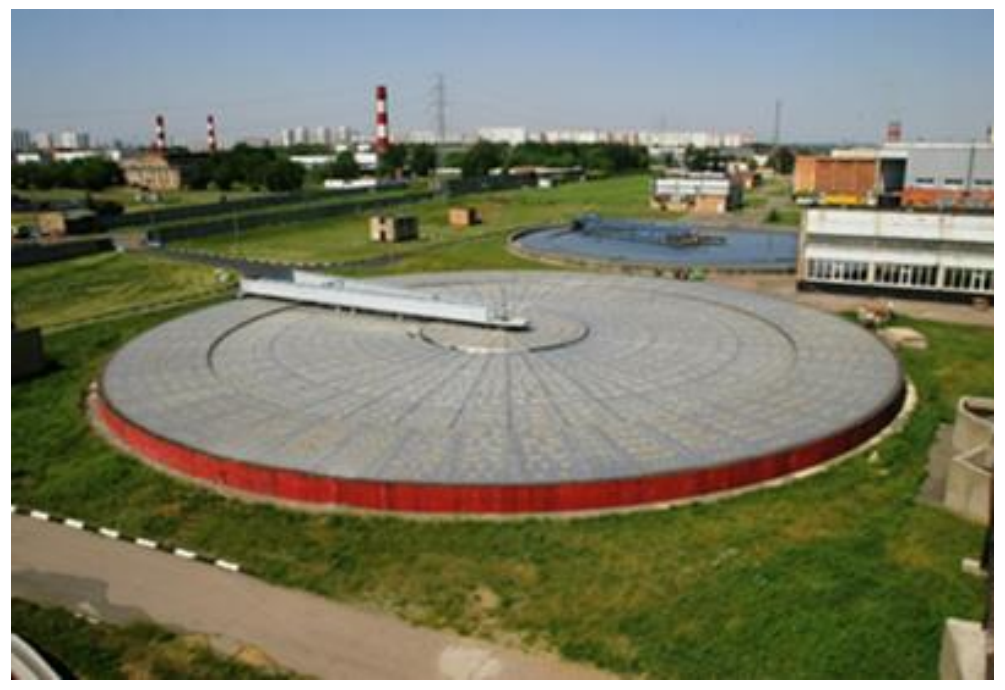

Fig. 2. Example of a floating flooring at a primary sedimentation tank

For this purpose, in 2013, as a part of an industrial field experiment, a particular floating flooring with a diameter of $54 \mathrm{~m}$, which has been developed in this country, was installed at one of the primary sedimentation tanks of local treatment facilities. Its tests were successful: the emission of fetidly smelling emissions decreased by $94 \%$.

\subsection{Methods of odor control using chemical reagents}

In the world practice, a big experience in dealing with fetidly smelling gases has been got. Fetid smells may be deodorized using the reagents that change the nature of the odor or reduce its intensity. Therefore, unpleasant odors disappear, or at least are characterized by high thresholds of the olfactory susceptibility.

The most commonly used deodorization methods are sorption, biological gas purification, thermal and catalytic combustion, and odor neutralization. Currently, hydrogen peroxide $\mathrm{H}_{2} \mathrm{O}_{2}$, chlorine, ozone, and potassium permanganate are used to effectively reduce odor emissions [21]. The most environmentally friendly reagent is hydrogen peroxide due to the lack of formation of harmful by-products which drop down into the sediment. In this case, the reaction products are water and carbon dioxide $\mathrm{CO}_{2}$. At the same time, hydrogen peroxide is quite versatile, providing oxidation of organic compounds of various groups. When removing sulfides, the effect of using hydrogen peroxide reaches $85-100 \%$, leaving water and oxygen as by-products [22, 23].

Another effective oxidizer of gas odorous substances is ozone. The advantage of the ozonation method is that ozone affects almost all types of odorous compounds. The ozone generation can be performed either directly in the air stream to be treated in a special reaction chamber, or in ozonators with subsequent introduction of ozone into the air stream to be treated.

When deodorizing chlorine-containing compounds, restrictions may occur due to the potential formation of organic halogen-based substances, such as carcinogenic trihalomethanes. However, chlorine is useful for reducing sulfur to sulfates. At the same time, organic substances are oxidized in wastewater as well, that leads to a smaller biochemical oxygen consumption. Sodium hypochlorite effectively removes the smell of ammonia, disinfects water and destroys cyanides. Chlorine dioxide is also effective for treating waste water from sulfides, phenols, and mercaptans (thiols). 
Practice shows that potassium permanganate $\left(\mathrm{KMnO}_{4}\right)$ is a strong oxidizer that can convert sulfides into sulfates, as well as oxidize organic substances that cause odors. However, the high cost of this reagent leads to restrictions on its use. The $\mathrm{pH}$ value of the wastewater plays an important role in oxidation processes; the optimal range is the $\mathrm{pH}$ value of $6,5-7,0[6]$.

The fight against odors can also consist in the use of salts containing nitrates, which help to regulate the sediment decay processes. The principle of regulation is that the addition of nitrates in the wastewater prevents formation of anaerobic conditions. The procedure involves dosing a liquid solution of calcium nitrate or iron into the wastewater stream before it inflows the pumping stations. The dosage control is the indispensable condition so that a certain amount of nitrates remains in the wastewater, but no more than traces of them. This guarantees the prevention of anaerobic conditions that lead to additional costs at the subsequent stages of the wastewater treatment [2]. A common disadvantage of using chemical reagents is their high cost.

\section{Conclusions}

1. The basis of odors in the wastewater are existing organic substances that are quantitatively determined by the values of biochemical (BLC) and chemical (CLC) need for oxygen. When decomposed, these substances are partially converted into volatile compounds that have a strong and unpleasant smell.

2. The appearance of unpleasant odors in the atmospheric air of cities is often caused by the presence of uncontrolled deposits in sewer pipes, wells, collectors and the receiving tanks of pumping stations, i.e. in constructions transporting wastewater to treatment facilities.

3. For gravity sewer pipelines with a small diameter, a decrease in the wastewater oxygen concentration below $0,1 \mathrm{mg} / 1$ makes the critical conditions for the appearance of volatile substances. The gases that are formed in the wastewater have a high solubility. Drop wells, turns, sharp changes in diameters and in water temperatures in the pipeline lead to a violation of the phase equilibrium and, as a result, to the emission of gases into the atmospheric air through the leaky covers of wells.

4. As a rule, the smell enters the environment through the well shafts, ventilation systems of pumping stations that are not equipped with means of neutralizing gas emissions, from open surfaces of treatment facilities, as well as the sewer pipeline failures.

5. Prevention of fetid gas emissions into the atmosphere can be achieved either by constructive methods or by dosing reagents. The optimal and most effective method can be selected for each case.

\section{References}

1. H. Kim, S. Murthy, L. McConnell, C. Peot, R. Ramirez, M. Strawn. Characterization of wastewater and solids odors using solid phase microextraction at a large wastewater treatment plant Water Sci. Technol. 46 pp. 9-16 (2002)

2. Odours in Wastewater Treatment. Measurement. Modelling and Control Edited by Richard Stuetz, School of Water Sciences, Cranfield University (UK) and Franz-Bernd Frechen, Department of Sanitary and Environmental Engineering, University of Kassel (Germany) p. 452 (2000)

3. P. Gostelow, S. A. Parsons, Sewage treatment works odour measurements, Water Sci. Technol, 41, pp. 33-40 (2000)

4. J.O. Johnsen, C.M. Wathes, Concentrations and Emissions of Ammonia in Livestock Buildings in Northern Europe, J. Agric. Eng. Res., 70, pp. 79-95 (2012) 
5. Electronic resource. URL: https://present5.com/perspektivy-razvitiya-iekonomicheskaya-celesoobraznost-biogazovyx-texnologij-v/ (free accessed 08.12.2019)

6. J.M. Estrada, B. Kraakman, R. Muñoz, R. Lebrero, Comparative Analysis of Odour Treatment Technologies in Wastewater Treatment Plants, Environ. Sci. Technol. 45, pp. 1100-1106 (2010)

7. Kamil Pochwat, Małgorzata Kida, Sabina Ziembowicz and Piotr Koszelnik Odours in Sewerage, A Description of Emissions and of Technical Abatement Measures Environments, 6,8, pp. 89-92 (2019)

8. Electronic resource. URL: http://os.x-pdf.ru/20ekonomika/778100-1-himiya-prirodnihsoedineniy-uchebnoe-posobie-dlya-studentov-fakul.php (free accessed 01.11.2020)

9. Electronic resource. URL: http://encyclopaedia.biga.ru/enc/science_and_technology/AMMIAK.html (free accessed 04.11.2020)

10. GOST 32673-2014 of the Russian Federation Rules for setting standards and controlling emissions of foulsmelling substances into the atmosphere

11. Electronic resource. Access code: http://odorlab.ru/production/nasal-ranger/ (free accessed 01.11.2020)

12. SP 30.13330.2016 Internal water supply and Sewerage of buildings. Updated version of SNiP 2.04.01-85* Publishing house of the Ministry of regional development of Russia p. 140 (2016)

13. V.A. Orlov, I.S. Khantaev, E.V. Orlov, Trenchless technologies, Publishing house ASV p. 224 (2016)

14. O.G. Primin, E.I. Pupyrev, Methods for improving the environmental safety of pipelines of sewer networks Ecology and industry in Russia, 3, pp. 13-17 (2013)

15. J. Joyce, Implementing Vapor Phase Odor Control on Large Diameter Interceptor Systems Biosolids and Odor and Corrosion, Conference \& Expo (Germany), pp. 1-31 (2013)

16. H. Sorenson, Odor Control for Large Diameter Deep Sewer Tunnels - The City of Columbus, Ohio. In Odors and VOC Emissions, Proceedings of the Water Environment Federations Specialty Conference. Cincinnati, pp. 112-147 (2000)

17. W.J. Parker, A Tracer Study of Headspace Ventilation in a Collector Sewer, Journal of the Air \& Waste Management Association, 4, pp. 581-592 (2011)

18. SP 32.13330.2012 Set of rules. Sewerage. Outdoor networks and structures. Updated version of SNiP 2.04.03-85, Publishing house of the Ministry of regional development of Russia pp. 122 (2012)

19. Standard ATV-DVWK-A 157:2000-11 Bauwerke der Kanalisation (2000)

20. A.N. Pakhomov, A.B. Bitiev, C.A. Streltsov, Minites on biogas: experience of MOSVODOKANAL Energy Security and energy saving, 3,27, pp. 22-24 (2009)

21. I. Wysocka, J. Gębicki, J. Namieśnik. Technologies for deodorization of malodorous gases, Environ. Sci. Pollut., 26, pp. 9409-9434 (2019)

22. L. Capelli, S. Sironi, Predicting odour emissions from wastewater treatment plants by means of odour emission factors, Water Res., 43,7, pp. 1977-1985 (2009)

23. M. Dębowski, M. Zieliński, The use of Fenton's reaction to limit the process of creaming and formation of hydrogen sulphide in municipal wastewater, Annu. Set Environ. Prot., 10, pp. 289-300 (2008) 